\title{
Effect of pallet unit-controlled atmosphere packaging in maintaining the quality of kimchi cabbage (Brassica rapa L. ssp. pekinensis) harvested in the summer
}

\author{
Eun Ji Choi ${ }^{1}$, Hae Woong Park ${ }^{1}$, Jeong Hyeon Lee ${ }^{1,3}$, Hong Kyeong Kim ${ }^{1}$, \\ Chun Wan Park ${ }^{2}$, Kyung Bin Song ${ }^{3}$, Ji Hoon Kang ${ }^{3}$, Jun Beom Park ${ }^{3}$, \\ Hyuk-je Woo ${ }^{3}$, Ho Hyun Chun ${ }^{1 *}$ \\ ${ }^{1}$ Advanced Process Technology and Fermentation Research Group, World Institute of Kimchi, Gwangju 61755, Korea \\ ${ }^{2}$ Division of Postharvest Engineering, National Academy of Agricultural Science, Wanju 55365, Korea \\ ${ }^{3}$ Department of Food Science and Technology, Chungnam National University, Daejeon 34134, Korea
}

\section{여름 배추의 품질 유지를 위한 pallet unit-controlled atmosphere 포장 효과}

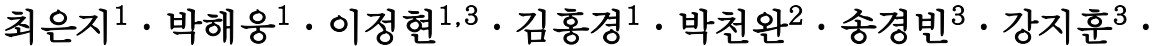 \\ 박준범 ${ }^{3} \cdot$ 우혁제 $^{3} \cdot$ 천호현 $^{1 *}$ \\ ${ }^{1}$ 세계김치연구소 신공정발효연구단, ${ }^{2}$ 국립농업과학원 수확후관리공학과, ${ }^{3}$ 충남대학교 식품공학과
}

\begin{abstract}
The effects of the pallet unit-controlled atmosphere (PUCA) packaging system on the physicochemical quality and physiological changes in the kimchi cabbage (Brassica rapa L. ssp. pekinensis) harvested in summer, during cold storage at $2^{\circ} \mathrm{C}$ were examined. PUCA packaging delayed the weight loss and trimming loss of kimchi cabbages during storage, irrespective of the $\mathrm{O}_{2}$ and $\mathrm{CO}_{2}$ concentrations. In addition, the cabbages stored using the PUCA packaging at $0.5 \% \mathrm{O}_{2}+2 \% \mathrm{CO}_{2}, 2 \% \mathrm{O}_{2}+2 \% \mathrm{CO}_{2}$, and $2 \% \mathrm{O}_{2}+10 \% \mathrm{CO}_{2}$ exhibited lower intemal disorder/decay incidence rate than the control, and maintained the moisture content. The total phenolic content of the cabbages with PUCA packaging exposed to $2 \% \mathrm{O}_{2}+2 \% \mathrm{CO}_{2}$ was higher after 80 days of storage compared to cabbages stored in the control conditions and in the PUCA packaging at $0.5 \% \mathrm{O}_{2}+2 \% \mathrm{CO}_{2}$ or $2 \% \mathrm{O}_{2}+10 \% \mathrm{CO}_{2}$. $\mathrm{No}^{2}$ significant $(\mathrm{p}>\mathbf{0 . 0 5})$ differences were observed in the $\mathrm{pH}$, firmness, reducing sugar content, soluble solids content, and total glucosinolate content of the control and PUCA packaging samples during storage for 80 days. Therefore, these results indicate that the PUCA packaging system, at appropriate gas concentrations, can be useful in maintaining the quality of kimchi cabbage during long-term storage.
\end{abstract}

Key words : kimchi cabbage, controlled atmosphere, storage, quality, weight loss

\section{서 론}

국내 배추 생산량은 2016년 기준 약 240만 톤으로 중국, 인도, 러시아에 이어 세계 4 위이며 배추김치, 절임배추 또

*Corresponding author. E-mail : hhchun@wikim.re.kr Phone : 82-62-610-1761, Fax : 82-62-610-1850

Received 25 January 2019; Revised 09 May 2019; Accepted 20 May 2019.

Copyright (c) The Korean Society of Food Preservation. All rights reserved.
는 쌈 채소 등으로 연중 소비되고 있기 때문에 안정적인 저장이나 유통이 매우 중요한 채소이다 $(1,2)$. 특히 2017년 농림축산식품부에서 발간한 "2017 식품산업 원료소비 실 태조사"에 따르면 2016년 국내 배추 생산량은 179만 톤으 로 총 생산량의 $90 \%$ 이상이 배추원물 상태로 유통되며 이중 약 $84 \%$ 가 김치 원료로서 이용되고 있다(3).

국산 배추는 계절별 노지 또는 하우스 봄배추, 고랭지 여름배추, 김장용 가을배추와 월동 겨울배추로 분류되어 연중 생산되고 있지만 배추 가격은 기상이변, 재배면적, 작황 또는 계절별 출하량 등 생산 변동 요인에 의해 민감하 
게 반응한다(4). 최근 몇 년간 여름철에 폭염과 집중호우로 인해 강원지역 준고랭지와 고랭지 배추의 생산량 변동이 심하였으며 저장도 1 개월 이상 어렵기 때문에 배추 수급이 불안정하였다. 반면 10-11월에 수확하는 가을배추의 경우, 밭에서 겉잎 제거와 그물망 포장 후 바로 시장에 출하하기 때문에 생산량이 많은 시기에는 가격이 폭락하면서 산지폐 기가 행해지고 있다(5). 현재 김치제조업체의 배추 원재료 수급에 재배농가와 산지유통센터가 원재료 조달 시장에 참여하고 있다(6). 그러나 매년 반복적으로 발생하는 배추 가격 급등과 물량 부족 현상은 김치 시장구조에 부정적 영향을 미치며 소비자 물가 상승으로 반영되고 있는 실정이 다(7).

농산물산지 유통센터나 김치제조업체에서는 수확 후 배 추를 플라스틱 박스나 망 포장하여 $0-4{ }^{\circ} \mathrm{C}$ 냉장온도에서 저 장하는 방법을 주로 사용하고 있다(8). 그러나 배추는 호냉 성 채소로 올바르지 못한 저장환경에 노출되면 호흡이 지속 적으로 증가하기 때문에 호흡열에 의한 품온 상승과 미생물 증식으로 부패가 발생한다(9). 또한 호흡 과정 중 배추 잎의 기공을 통해 수분을 체외로 발산시키는 증산작용은 저장 중 배추의 중량을 감소시키고 선도와 품질의 저하를 촉진할 수 있다(10). 따라서 이를 해결하기 위한 근본적인 대책으로 배추 저장기간 연장 기술개발이 시급하다.

Controlled atmosphere(CA) 저장은 농산물을 저장고에 입 고하여 밀폐시킨 후 질소발생기를 이용하여 저장고 내 $\mathrm{O}_{2}$ 와 $\mathrm{CO}_{2}$ 농도를 제어함으로써 농산물의 호흡 억제와 노화를 지연할 수 있는 기술이다 $(11,12)$. 그러나 현재 보급되어 있 는 국내 저온 저장고는 습도와 기체 환경 조절이 가능하지 않고 기밀(air tightness)이 확보되지 않아 시설형 CA 기술 적용이 매우 제한적이다(13). 한편 pallet unit-controlled atmosphere(PUCA) 저장 시스템은 pallet별로 적재된 농산 물을 플라스틱 필름으로 기밀 포장하고 포장 내부의 기체 환경을 조절함으로써 다른 pallet 조건에 영향을 주지 않으 면서 출하가 가능하다. 또한 시설형 $\mathrm{CA}$ 저장고과 비교하여 PUCA 저장 시스템은 초기 설치비와 유지비가 저렴하며 기존 저온 저장고를 이용할 수 있기 때문에 현장 적용성이 우수하다.

2018년 Osher 등(14)은 CA 저장이 일반 저온 저장과 비교 하여 Pruktor와 Cheers 품종 배추의 중량 감소, 부패 및 생리 적 저장 장해 발생을 감소시켰다고 보고하였다. 또한 $\mathrm{Zhu}$ 등(15)은 modified atmosphere vacuum cooling 전처리가 저 장 중 배추의 호흡률 감소, peroxidase와 catalase 활성 조절 에 효과가 있음을 발표하였다. 현재까지 국내에서는 국산 배추의 저장성 향상을 위한 포장 및 적재 방법 개선(16), pallet unit-modified atmosphere packaging과 플라즈마 복합 처리(17), 차압식 예냉 전처리(18), 1-MCP 화학적 방법(19) 연구는 수행된 바 있지만 저온 저장시설 내 배추의 pallet 적재 단위별 적정 기체조성을 유지할 수 있는 controlled atmosphere packaging 시스템 개발 관련 연구는 수행된 바 없다.

따라서 본 연구는 기존 저온 저장고 내에 배추의 pallet 적재 단위에 적용 가능한 controlled atmosphere packaging 시스템을 개발하였다. 또한 개발한 저장 시스템은 여름배 추에 적용하여 저장 중 배추의 중량 감모율, 정선 손실률, 호흡률 및 이화학적 품질 변화 분석을 통해 저장 안정성 증대 효과를 구명하고자 하였다.

\section{재료 및 방법}

\section{실험재료}

본 실험에 사용한 여름배추(Brassica rapa L. ssp. pekinensis) 시료는 2018년 7월 강원 삼척에서 수확한 ‘춘광' 품종을 광주 남구 소재 농수산물 도매시장에서 구입하였다. 배추 시료는 HDPE 박스 $(55 \mathrm{~cm} \times 37 \mathrm{~cm} \times 32 \mathrm{~cm})$ 에 5 포기씩 세워 담아 포장 후 $5 \pm 1^{\circ} \mathrm{C}$ 에서 예냉처리를 12 시간 이상 실시하였 다.

\section{Pallet unit-controlled atmosphere packaging (PUCA) 시스템 구성 및 설치 방법}

본 연구에서 개발한 PUCA 시스템의 구조와 제원은 Fig. 1에 나타냈다. PUCA 시스템은 polysulfone membrane type 질소 발생기(Airrane Inc., Cheongju, Korea), 기체 제어 programmable logic controller (PLC, DDC-478, Systronics Co., Bucheon, Korea), 온도, 습도, $\mathrm{O}_{2}$ 와 $\mathrm{CO}_{2}$ 동시 측정하는 통합센서(SH-VT-250-O 2 , Sohatech Co., Seoul, Korea)로 구 성하였다. 약 $25 \mathrm{~m}^{2}$ 저온 저장고 내 배추가 담긴 $\mathrm{HDPE}$ 박스는 pallet 위에 5단(6박스/단)으로 적재하고 polyamide 필름(두께: $0.1 \mathrm{~mm}$ )으로 포장 후 기밀(air tightness)을 확인 하였다. $\mathrm{N}_{2}, \mathrm{O}_{2}$ 와 $\mathrm{CO}_{2}$ 는 질소발생기, $40.2 \mathrm{~L} \mathrm{O}_{2}$ 와 $40.2 \mathrm{~L}$ $\mathrm{CO}_{2}$ 가스용기에 각각 연결한 $12 \mathrm{~mm}$ 에어호스를 통해 pallet 필름 포장 내부에 각각 주입시키고 에어호스에 설치한 밸브 와 PLC를 이용하여 기체의 주입량을 조절할 수 있도록 하였다. 또한 필름 포장 내부에 환기팬을 작동시켜 주입된 기체의 혼합 및 순환을 유도하였다. $\mathrm{CA}$ 저장을 위한 기체 환경 조건은 배추의 기체 환경 조절 저장 관련 국내외 선행 연구 $(14,15,17)$ 를 참고하여 $0.5 \% \mathrm{O}_{2}+2 \% \mathrm{CO}_{2}, 2 \% \mathrm{O}_{2}+$ $2 \% \mathrm{CO}_{2}$ 와 $2 \% \mathrm{O}_{2}+10 \% \mathrm{CO}_{2}$ 로 설정하였으며 각각을 $\mathrm{PUCA} 1, \mathrm{PUCA} 2$ 와 PUCA3으로 명명하였다. $2 \pm 1^{\circ} \mathrm{C}$ 에서 80 일간 저장하면서 배추의 생리적 특성, 이화학적 품질과 기 능성 성분 분석은 20 일 간격으로 수행하였다. 일반적인 대 기환경에서 저장한 배추 시료는 대조구로 하였다.

저장 중 여름배추의 중량 감모율과 정선 손실률 분석

배추의 중량 감모율은 저장 전 시료의 초기중량을 측정 


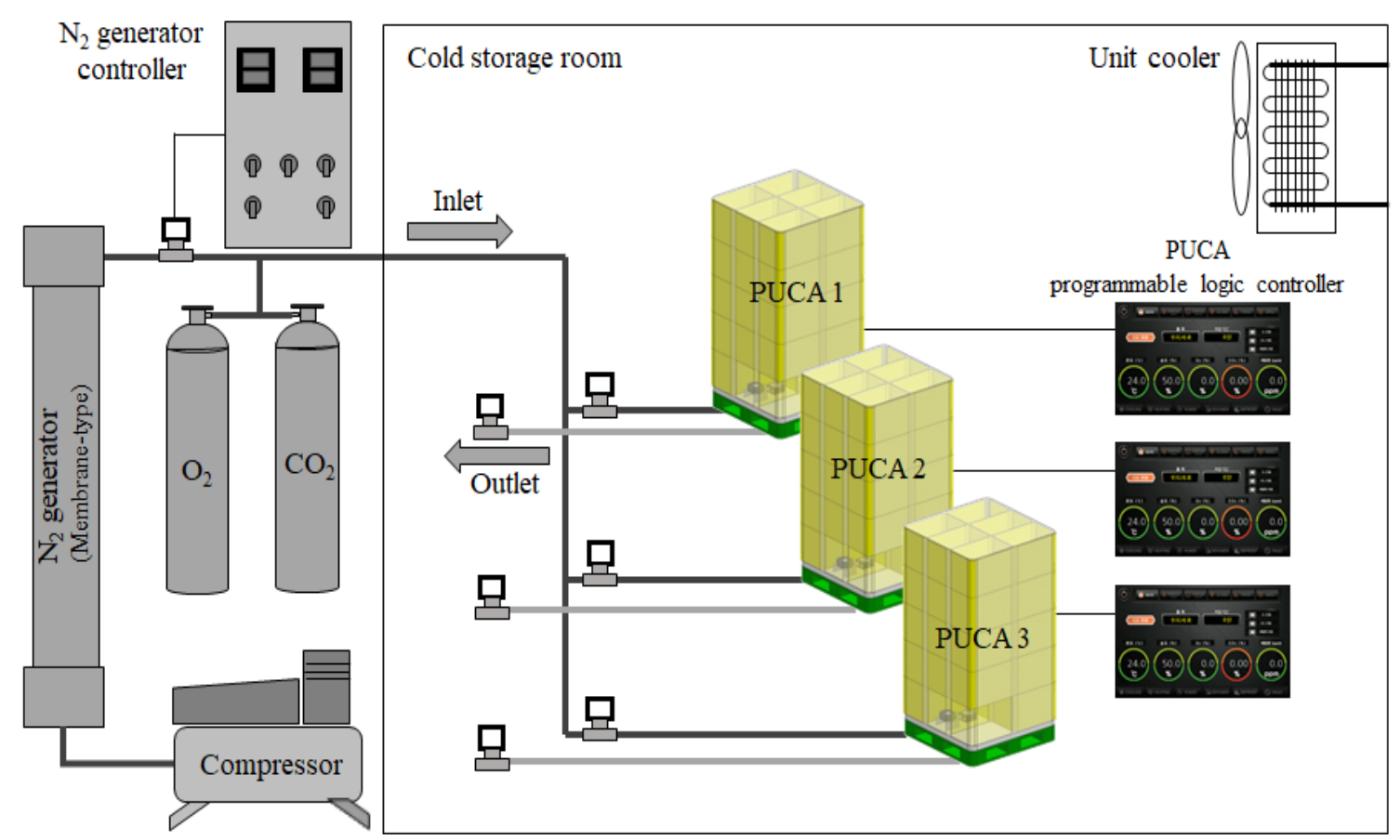

Fig. 1. Schematic representation of pallet unit-controlled atmosphere packaging system.

한 후 저장기간 중 감소한 시료의 중량을 초기중량에 대한 백분율로 환산하여 나타내었다(20). 저장 중 배추의 정선 손실률은 배추의 중량과 부패 및 건조되어 배추김치 제조에 이용할 수 없는 배추 겉잎을 제거한 후 중량 변화를 백분율 로 환산하여 나타내었다(21).

\section{저장 중 여름배추의 내부 장해 및 부패 발생률 분석}

배추의 내부 장해 및 부패 발생률 조사를 위해 저장 0 , $20,40,60$ 과 80 일차에 각각 무작위로 선택한 시료 20 포기는 횡단면으로 절단 후 시료에 내부갈변과 곰팡이 및 짓무름 (부패) 발생을 확인하였다. 내부 장해 및 부패 발생률은 장해가 발생한 시료 수를 저장 80 일까지 누적하여 전체 조사 100 포기 시료에 대한 백분율로 나타내었다.

\section{저장 중 여름배추의 호흡률 변화 분석}

수확한 배추의 호흡률은 이산화탄소 생성율 또는 산소 소비율로 나타낼 수 있다(22). 본 연구에서는 Fonseca 등 (23)과 Yang 등(24)에서 제시한 방법을 이용하여 배추 시료 의 호흡률을 분석하였다. 진공 desiccator(T403040, Tarsons Product Ltd., Rajpur Sonarpur, India)에 배추 1포기를 넣은 후 외부 기체가 유입될 수 있는 밸브는 septum으로 완전히 밀폐시켰다. $25^{\circ} \mathrm{C}$ 실온에서 단위 시간당 배추 호흡에 의해 증가한 이산화탄소 농도(\%)는 headspace gas analyser (Checkpoint 3 premium, Dansensor, Ringsted, Denmark)를 이용하여 측정하였고 배추의 호흡률 $(\mathrm{mL} \mathrm{CO} / \mathrm{kg} \cdot \mathrm{h})$ 은 아래 의 수식을 이용하여 산출하였다.
Respiration rate $\mathrm{CO}_{2}(\mathrm{~mL} \mathrm{CO} / \mathrm{kg} \cdot \mathrm{h})=$

(final $\mathrm{CO}_{2}$ concentration-initial $\mathrm{CO}_{2}$ concentration) $\times \mathrm{V}$ $100 \times \mathbf{M} \times($ measured time-intial time $)$

$\mathrm{V}$ : the volume of desiccator

$\mathrm{M}$ : the mass of kimchi cabbage

저장 중 여름배추의 $\mathrm{pH}$, 수분 함량, 기계적 경도 변화 분석

배추의 $\mathrm{pH}$ 와 수분 함량 분석을 위한 시료 전처리를 위해 정선한 배추는 blender(HR1390, Philips, Guangzhou, China) 를 이용해 3 분간 균질화하였다. 균질한 시료의 $\mathrm{pH}$ 는 $\mathrm{pH}$ meter(TitroLine 5000, SI Analytics, Mainz, Germany)를 이용 하여 $\mathrm{pH}$ 표준 용액 보정 후 실온에서 측정하였다. 수분 함량은 시료 $1 \mathrm{~g}$ 을 aluminum weighting dish에 취한 후 적외 선 수분측정기(MB45, Ohaus Co., Pine Brook NJ, USA)를 이용하여 측정하였다.

배추 시료의 기계적 경도는 줄기 부분을 $4 \mathrm{~cm} \times 4 \mathrm{~cm}$ 크기 로 절단 후 texture analyzer(TA-XT2, Stable Micro System Ltd., Surrey, UK)를 사용하였으며 지름 $2 \mathrm{~mm}$ cylindrical probe가 $0.5 \mathrm{~mm} / \mathrm{s}$ test speed와 $10 \mathrm{~mm}$ 깊이로 엽육을 통과시 킬 때 얻어지는 최대값을 $\mathrm{kgf}$ 으로 나타내었다. 경도의 측정 횟수는 각 저장 조건 별 배추 시료를 무작위로 5 개 선발하여 3회 반복하였다. 
저장 중 여름배추의 환원당 함량과 가용성 고형물 함량 변화 분석

배추 시료의 환원당 함량은 dinitrosalicylic acid(DNS) 방 법(25)을 이용하여 분석하였다. 균질한 시료를 50 배 희석 후 시료 용액 $1 \mathrm{~mL}$ 에 $\mathrm{DNS}$ 시약 $3 \mathrm{~mL}$ 를 넣고 $100^{\circ} \mathrm{C}$ water bath에서 5 분 동안 가열 후 실온에서 냉각하였다. 냉각한 시료용액에 증류수 $16 \mathrm{~mL}$ 를 넣고 혼합 후 분광광도계 (UV-1800, Shimadzu Scientific Instruments Inc., Columbia, $\mathrm{MD}, \mathrm{USA}$ )를 사용하여 $550 \mathrm{~nm}$ 에서 흡광도를 측정하였으며 이때 사용한 DNS 시약의 표준곡선에 의해 glucose 함량을 산출하여 $\mathrm{mg} / \mathrm{g}$ 로 나타냈다.

가용성 고형물 함량은 균질한 배추 시료를 디지털 굴절 당도계(PAL-1, Atago, Tokyo, Japan)로 상온에서 측정하여 ${ }^{\circ} \mathrm{Brix}$ 로 나타내었다.

저장 중 여름배추의 총 페놀 화합물 함량과 총 glucosinolates 함량 변화 분석

배추의 총 페놀 화합물 함량은 Folin-Denis 방법(26)을 이용하여 분석하였다. 동결 건조된 배추 시료 $0.5 \mathrm{~g}$ 에 $80 \%$ methanol $50 \mathrm{~mL}$ 를 혼합(1:100, w/v) 후 shaking incubator(2 $5^{\circ} \mathrm{C}, 150 \mathrm{rpm}$ )에서 24 시간 동안 추출하였다. 추출 용액 100 $\mu \mathrm{L}$ 에 증류수 $2.5 \mathrm{~mL}$ 와 Folin-Ciocalteu's reagent $100 \mu \mathrm{L}$ 를 혼합하여 30 초 반응시킨 후 $20 \%$ sodium carbonate $300 \mu \mathrm{L}$ 를 첨가하여 $20^{\circ} \mathrm{C}$ 에서 1 시간 동안 추가 반응시켰다. 반응 용액 은 spectrophotometer(UV-2450, Shimadzu Co., Kyoto, $\mathrm{Japan}$ )를 이용하여 $765 \mathrm{~nm}$ 에서 흡광도를 5 회 반복 측정하 였으며 총 페놀 화합물 함량은 $\mathrm{mg}$ gallic acid equivalent $(\mathrm{GAE}) / 100 \mathrm{~g}$ dry weight(DW)로 나타내어 표시하였다.

배추의 총 glucosinolates 함량 분석을 위해 동결 건조된 배추 시료 $0.1 \mathrm{~g}$ 에 $70 \%$ methanol $1.5 \mathrm{~mL}$ 를 혼합(1:15, w/v) 후 shaking incubator $\left(25^{\circ} \mathrm{C}, 200 \mathrm{rpm}\right)$ 에서 24시간 동안 추출 하였다. 추출 용액은 $4^{\circ} \mathrm{C}$ 에서 $3,000 \times \mathrm{g}$ 로 8 분간 원심분리하 였으며 상등액 $100 \mu \mathrm{L}$ 에 증류수 $300 \mu \mathrm{L}$ 와 $2 \mathrm{mM}$ sodium tetrachloropalladate $3 \mathrm{~mL}$ 를 순서대로 넣은 후 $20^{\circ} \mathrm{C}$ 에서 1 시 간 반응시켰다. 반응 용액은 spectrophotometer(UV-2450, Shimadzu Co.)를 이용하여 $425 \mathrm{~nm}$ 에서 흡광도를 5회 반복 측정하였으며 아래의 수식을 이용하여 산출하였다.

Total glucosinolates content $(\mu \mathrm{mol} / \mathrm{g} \mathrm{DW})=1.40+118.86 \times \mathrm{A}_{425}$ $\mathrm{A}_{425}$ : the sample absorbance at $425 \mathrm{~nm}$

\section{통계처리}

모든 실험의 반복은 3회 이상 수행하였고 실험 결과는 평균값 \pm 표준편차로 표기하였다. 통계적 분석은 SPSS (Statistical Package for the Social Science, Version 19, SPSS Inc., Chicago, IL, USA) program을 이용하여 one-way ANOVA를 하였으며 사후검증으로 Duncan's multiple range test를 실시하여 $\mathrm{p}<0.05$ 수준에서 유의성 검증을 하였다.

\section{결과 및 고찰}

\section{저장 중 여름배추의 중량 감모율과 정선 손실률}

저온 저장 중 pallet unit 기체제어 포장한 여름배추의 중량 감모율 변화는 Fig. 2 에 나타내었다. $2^{\circ} \mathrm{C}$ 저장 40 일 후 대조구의 중량감모율은 급격히 증가하여 $18.07 \%$ 로 관찰 되었으며 PUCA 1-3 처리구와 비교하여 유의적인 $(\mathrm{p}<0.05)$ 차이를 보였다. 또한 저장 80 일 후 PUCA 1-3 처리구의 중량감모율은 $1.19-1.58 \%$ 로 대조구 $(29.07 \%$ ) 대비 약 $28 \%$ 차이를 보여 pallet unit 기체제어 포장이 저장 중 배추의 중량 감소 억제에 효과적인 것으로 나타났다. linear low density polyethylene(LLDP) 필름을 이용하여 pallet 단위로 modified atmosphere 포장한 봄배추의 저장 9주 후 중량감모 율이 $3.07 \%$ 로 나타나 중량 손실이 효과적으로 억제되었다 는 Lee 등(13)의 보고는 본 연구결과와 유사하였다. 배추는 94\% 이상 높은 수분을 함유하고 있어 수증기에 의해 포화 된 세포 간극 내 내부공기와 불포화된 외부공기 사이의 수증기압 차이로 수분 증발이 일어난다(17). 저장 중 배추는 증산작용에 의해 중량 감소가 발생하며 배추의 중량이 약 $10 \%$ 이상 감소하면 위조현상이 발생하여 김치 가공적성에 부정적인 영향을 미친다 $(4,13)$. 본 연구 결과, 저장 중 대조 구에 비해 PUCA 처리구에서 중량 변화가 작았는데 이는 기체제어 포장 내부의 높은 상대습도와 호흡 억제에 기인하 는 것으로 판단된다.

생산지에서 도소매시장으로 유통 시나 배추김치 제조 시 저장된 배추의 건조되거나 부패된 겉잎을 제거하기 때문 에 정선 손실이 발생한다(21). Pallet unit 기체제어 저장

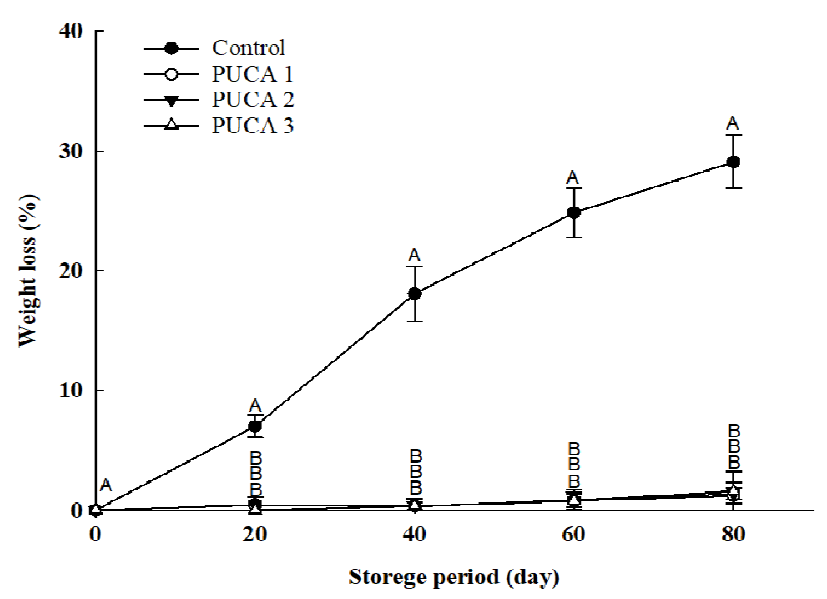

Fig. 2. Changes in the weight loss of the kimchi cabbages treated with pallet unit-controlled atmosphere packaging during storage. Each point represents the mean for triplicates and error bars show standard deviations. Means with different letters differ significantly $(p<0.05)$ within the same storage day. 
중 여름배추의 정선 손실률 변화는 Fig. 3에 나타내었다. 저장 초기 대조구의 정선손실률은 $19.55 \%$ 이었지만 저장기 간이 경과함에 따라 유의적으로 $(\mathrm{p}<0.05)$ 증가하여 저장 40 과 80 일 후 각각 36.43 과 $48.63 \%$ 를 나타냈다. 반면 저장 80 일 후 PUCA 1, 2 와 3 처리구는 각각 $26.13,25.68$ 와 $26.54 \%$ 의 정선손실률을 보여 대조구와 비교하여 약 2 배 낮은 정선손실률을 나타났다. Lee 등(13)은 LLDPE 기능성 필름을 이용하여 pallet 단위로 봄배추를 커버링 처리하였 을 때 저장 6 주까지 배추의 정선손실을 효과적으로 억제하 였다고 보고하였는데 본 연구결과와 유사하였다.

따라서 본 연구에서 개발한 pallet unit 기체제어 포장 기술은 여름배추의 초기 중량 및 정선손실 유지가 저장 2개월 이상 가능함으로써 김치산업 현장에서 여름별 김치 원료 수급과 가격 불안정에 대비할 수 있을 것으로 사료된 다.

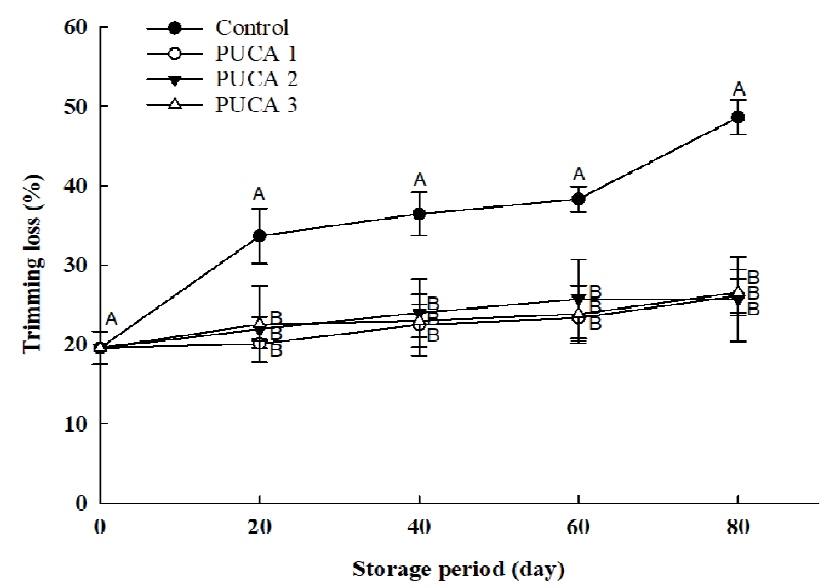

Fig. 3. Changes in the trimming loss of the kimchi cabbages treated with pallet unit-controlled atmosphere packaging during storage. Each point represents the mean for triplicates and error bars show standard deviations. Means with different letters differ significantly $(p<0.05)$ within the same storage day.

\section{저장 중 여름배추의 내부장해 및 부패 발생률}

배추는 품종, 재배 중 질소 시비량, 수확시기와 저장 중 부적절한 온도와 기체 환경 노출에 의해 중륵 갈변, 황화, 깨씨무늬증, 저온장해, 부패 미생물 또는 잿빛 곰팡이 증식 등이 발생할 수 있다(27). $2^{\circ} \mathrm{C}$ 저장 80 일 후 PUCA 1,2 와 3 처리구의 내부장해 및 부패 발생률은 각각 $19.05,17.39$ 와 $18.64 \%$ 를 나타냈다. 반면 대조구는 $27.27 \%$ 로 PUCA 1-3 처리구와 비교하여 유의적으로 $(\mathrm{p}<0.05)$ 높은 장해 및 부패 발생률을 보였다(Fig. 4).

특히 저장 40 일부터 대조구 시료 외관에서 심한 위조 현상이 관찰되었으며 내부 절단면에서 중륵 갈변 장해와 부패를 확인하였다(Fig. 5). 한편 저장 60일 이후 PUCA 1-3 처리구는 배추 겉잎에서만 곰팡이 증식과 짓무름이 나타났다. PUCA 1-3 처리구는 저장 중 polyamide 필름 포장
내부 상대습도가 $98 \% \mathrm{RH}$ 이상을 유지하였는데 이러한 높 은 습도 저장환경이 배추 겉잎에 존재하는 토양 유래 곰팡 이 생장에 유리하게 작용한 것으로 판단된다. Menniti 등 (28)은 polyvinyl chloride 필름 포장과 $1-3 \% \mathrm{O}_{2}+10 \% \mathrm{CO}_{2}$ $\mathrm{CA}$ 저장 방법 병용 시 저장 중 배추에 깨씨무늬증 발생을 효과적으로 억제한다고 보고하였다. 또한 Osher (14)등은 $3 \% \mathrm{O}_{2}$ 와 $6 \% \mathrm{CO}_{2} \mathrm{CA}$ 조건을 적용하여 배추를 90 일간 $1^{\circ} \mathrm{C}$ 에 서 저장한 결과 배추에 발생한 깨씨무늬 발생 지수가 일반 적인 대기 환경과 비교하여 낮은 결과를 발표하였다. Eum 등(18)은 $2{ }^{\circ} \mathrm{C}$ 저장 7 주 후 예냉과 high density polyethylene 필름으로 liner 처리한 여름배추의 내부에서 갈변이 발생하 였다고 보고하였다. Bahar 등(29)은 $5 \% \mathrm{O}_{2}$ 와 $5 \% \mathrm{CO}_{2}$ 조건 보다 $\mathrm{CO}_{2}$ 농도를 $15 \%$ 까지 높여 $\mathrm{CA}$ 저장했을 시 무화과 과육에 갈변이 발생하고 부패율이 증가했다고 보고하였다. 그러나 본 연구에서는 $\mathrm{CA}$ 포장 내부의 $\mathrm{CO}_{2}$ 농도를 $10 \%$ 로 유지하더라도 여름배추에 $\mathrm{CO}_{2}$ 저장 장해 발생은 확인되지 않았다. Eum 등(21)은 2011년 여름철에 수확한 국산배추의 경우 $25^{\circ} \mathrm{C}$ 상온 저장에서 무름병 증상이나 중륵 부위에 흑반 현상이 나타났으며 $0-5^{\circ} \mathrm{C}$ 저온 저장에서 수침, 흑반 또는 시들음 현상이 관찰되어 배추의 저장한계기간을 4 주 로 판단하였다. 반면 본 연구 결과, pallet unit 기체제어 포장 처리한 여름배추 시료는 $2^{\circ} \mathrm{C}$ 저장 80 일까지 저장 장해 로 판단되는 중륵 갈변이나 깨씨무늬증은 관찰되지 않았 다.

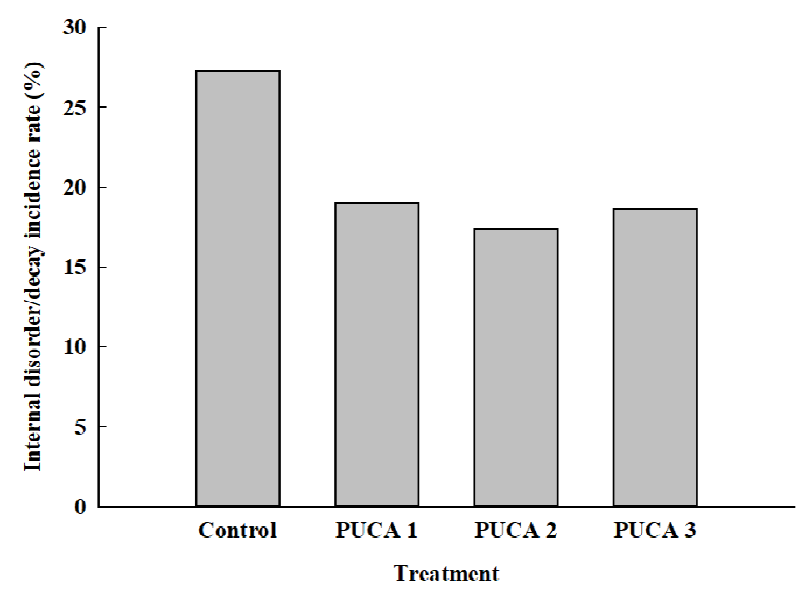

Fig. 4. Internal disorder/decay incidence rate of the summer kimchi cabbages stored in pallet unit-controlled atmosphere packaging for 80 days.

\section{저장 중 여름배추의 호흡률 변화}

농산물의 호흡은 수확 후 생리활성과 품질에 중요한 역 할을 한다(30). Pallet unit 포장 내부 $\mathrm{O}_{2}$ 와 $\mathrm{CO}_{2}$ 농도 조건을 달리하여 저장한 여름배추의 호흡률 변화를 분석한 결과는 Table 1에 나타냈다. 저장 초기 대조구의 호흡률은 31.18 $\mathrm{mL} \mathrm{CO} / \mathrm{kg} \cdot \mathrm{h}$ 이었는데 저장기간이 증가함에 따라 감소하 


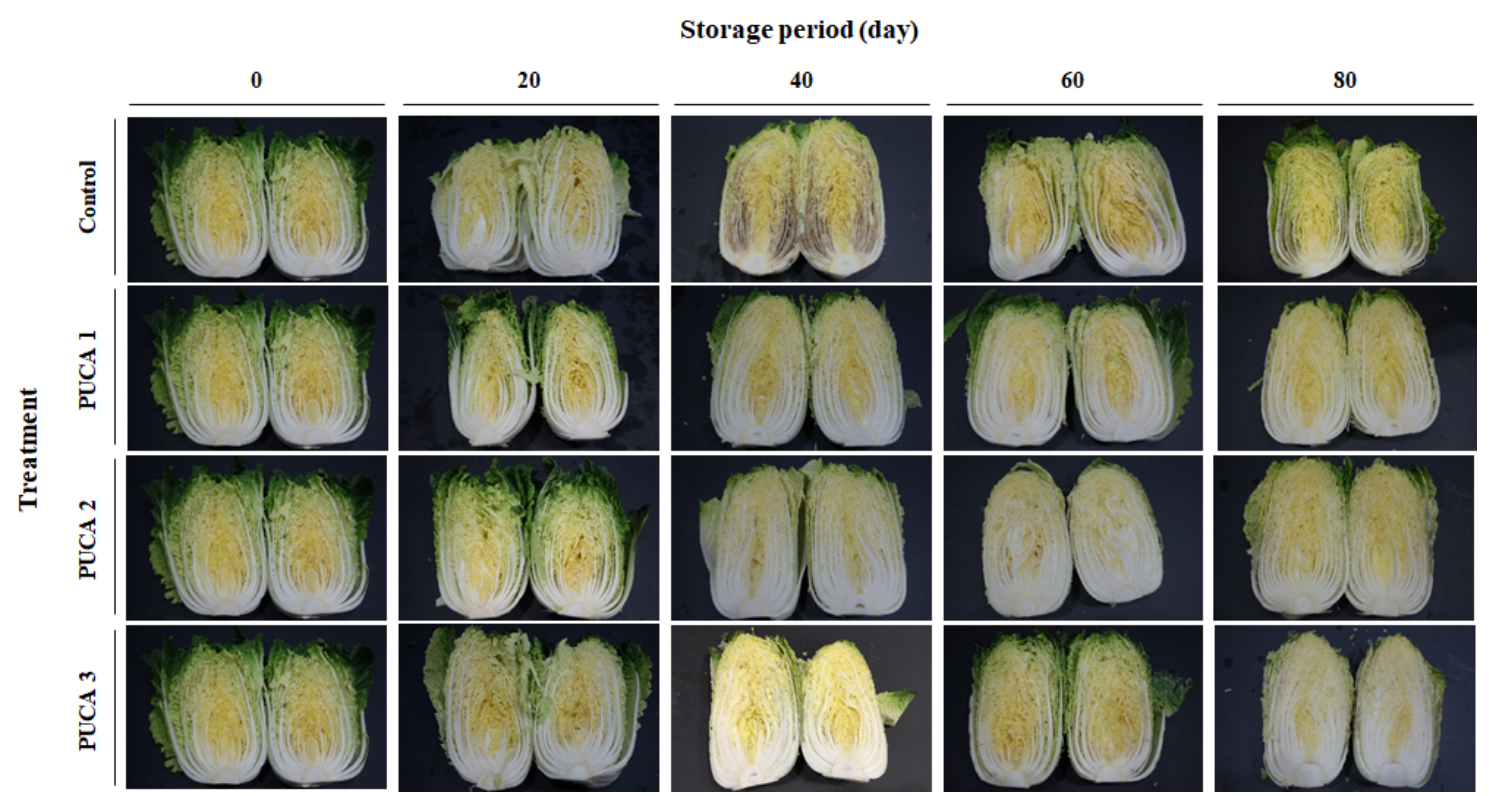

Fig. 5. Normal and post-internal disorder/decay shapes of the summer kimchi cabbages stored under air and controlled atmosphere conditions.

Table 1. Changes in the respiration rate of the summer kimchi cabbages treated with pallet unit-controlled atmosphere packaging during storage

\begin{tabular}{|c|c|c|c|c|c|c|}
\hline \multirow{2}{*}{ Parameter } & \multirow{2}{*}{ Treatment } & \multicolumn{5}{|c|}{ Storage period (day) } \\
\hline & & 0 & 20 & 40 & 60 & 80 \\
\hline \multirow{4}{*}{$\begin{array}{l}\text { Respiration rate } \\
(\mathrm{mL} \mathrm{CO} / \mathrm{kg} \cdot \mathrm{h})\end{array}$} & Control & $31.18 \pm 1.27^{4 / \mathrm{Aa} 5}$ & $20.55 \pm 6.24^{\mathrm{Bb}}$ & $19.41 \pm 3.75^{\mathrm{Bb}}$ & $15.31 \pm 4.80^{\mathrm{Bb}}$ & $15.75 \pm 6.28^{\mathrm{Bb}}$ \\
\hline & PUCA $1^{1)}$ & $31.18 \pm 1.27^{\mathrm{Aa}}$ & $22.20 \pm 3.34^{\mathrm{Bb}}$ & $17.37 \pm 2.71^{\mathrm{Bb}}$ & $17.86 \pm 3.47^{\mathrm{Bb}}$ & $17.27 \pm 2.97^{\mathrm{Bb}}$ \\
\hline & PUCA $2^{2)}$ & $31.18 \pm 1.27^{\mathrm{Aa}}$ & $22.22 \pm 3.92^{\mathrm{Bb}}$ & $19.35 \pm 4.20^{\mathrm{Bb}}$ & $23.30 \pm 3.60^{\mathrm{ABab}}$ & $23.76 \pm 7.07^{\mathrm{ABab}}$ \\
\hline & PUCA $3^{3)}$ & $31.18 \pm 1.27^{\mathrm{Aa}}$ & $32.92 \pm 2.12^{\mathrm{Aa}}$ & $30.23 \pm 2.36^{\mathrm{Aa}}$ & $28.15 \pm 4.79^{\mathrm{Aa}}$ & $33.43 \pm 4.65^{\mathrm{Aa}}$ \\
\hline
\end{tabular}

${ }^{1)} \mathrm{PUCA}$ 1: $0.5 \% \mathrm{O}_{2}+2 \% \mathrm{CO}_{2}$.

${ }^{2}$ PUCA 2: $2 \% \mathrm{O}_{2}+2 \% \mathrm{CO}_{2}$.

${ }^{3}$ PUCA 3: $2 \% \mathrm{O}_{2}+10 \% \mathrm{CO}_{2}$.

${ }^{4}$ Each value is mean $\pm \mathrm{SD}$.

${ }^{5}$ Mean values in the same column (A-B) or row (a-b) followed by different letters are significantly different according to Duncan's multiple range test $(\mathrm{p}<0.05)$

여 저장 80 일 후 $15.75 \mathrm{~mL} \mathrm{CO} / \mathrm{kg} \cdot \mathrm{h}$ 로 나타났다. PUCA 1 과 2 처리구의 호흡률도 저장 중 감소하여 저장 80 일 후 각각 17.27 과 $23.76 \mathrm{~mL} \mathrm{CO} / \mathrm{kg}$.h이었다. 저장기간 경과에 따른 배추 시료의 호흡률 감소는 노화 진행으로 인한 세포 의 생리적 기능과 대사 활동 저하와 관련이 있는 것으로 판단된다. 반면 저장 80 일 후 PUCA 3 처리구의 호흡률은 $33.43 \mathrm{~mL} \mathrm{CO} / \mathrm{kg} \cdot \mathrm{h}$ 로 저장 초기 수준을 유지하였으며 대조 구, PUCA 1 과 2 처리구와 비교하여 유의적으로 $(\mathrm{p}<0.05)$ 높은 값을 나타냈다.

일반적으로 하절기 고온에서 수확되는 여름배추가 가을 배추 또는 겨울배추에 비해 호흡속도가 빠르기 때문에 저장 성이 약한 경향이 있다.(14). 기체제어 저장 중 설정한 온도 와 $\mathrm{O}_{2}$ 와 $\mathrm{CO}_{2}$ 농도 조건은 배추의 호흡에 영향을 주는 중요 한 외부적 요인이며 저장 해제 후 배추의 생리적 변화에
따라 호흡 속도는 달라진다(31). Zhu 등(15)은 $7 \% \mathrm{O}_{2}$ 와 7\% $\mathrm{CO}_{2}$ 농도의 혼합기체를 이용한 modified atmosphere 진공 예냉 처리를 통해 저장 중 배추과 채소의 호흡이 억제되었 다고 보고하였다. 본 연구에서는 $2 \% \mathrm{O}_{2}$ 와 $10 \% \mathrm{CO}_{2}$ 조건이 pallet unit 기체제어 저장 중 여름배추의 호흡 유지와 노화 억제에 있어서 효과적인 기체 환경이라고 판단된다.

\section{저장 중 여름배추의 $\mathrm{pH}$, 수분 함량, 경도 변화}

Pallet unit 기체 제어 저장 중 여름배추의 $\mathrm{pH}$, 수분 함량과 경도 변화는 Table 2에 나타내었다. 저장 전 여름배추 시료 의 $\mathrm{pH}$ 는 6.14 이었다. 80 일 저장 경과 후 대조구의 $\mathrm{pH}$ 는 6.10 으로 저장기간에 따른 유의적인 차이가 나타나지 않았 다(p>0.05). PUCA 1-3 처리구의 $\mathrm{pH}$ 도 저장 중 6.01-6.20을 유지하면서 높은 $\mathrm{CO}_{2}$ 와 낮은 $\mathrm{O}_{2}$ 저장 환경에 의한 영향을 
Table 2. Changes in the $\mathrm{pH}$, moisture content, and firmness of the summer kimchi cabbages treated with pallet unit-controlled atmosphere packaging during storage

\begin{tabular}{|c|c|c|c|c|c|c|}
\hline \multirow{2}{*}{$\begin{array}{l}\text { Quality } \\
\text { parameter }\end{array}$} & \multirow{2}{*}{ Treatment } & \multicolumn{5}{|c|}{ Storage period (day) } \\
\hline & & 0 & 20 & 40 & 60 & 80 \\
\hline \multirow{4}{*}{$\mathrm{pH}$} & Control & $6.14 \pm 0.20^{4 \text { )Aas }}$ & $6.14 \pm 0.20^{\mathrm{Aa}}$ & $6.12 \pm 0.18^{\mathrm{Aa}}$ & $6.06 \pm 0.20^{\mathrm{Aa}}$ & $6.10 \pm 0.25^{\mathrm{Aa}}$ \\
\hline & PUCA $1^{1)}$ & $6.14 \pm 0.20^{\mathrm{Aa}}$ & $6.23 \pm 0.15^{\mathrm{Aa}}$ & $6.07 \pm 0.15^{\mathrm{Aa}}$ & $6.01 \pm 0.17^{\mathrm{Aa}}$ & $6.01 \pm 0.09^{\mathrm{Aa}}$ \\
\hline & PUCA 2) & $6.14 \pm 0.20^{\mathrm{Aa}}$ & $6.20 \pm 0.23^{\mathrm{Aa}}$ & $6.18 \pm 0.18^{\mathrm{Aa}}$ & $6.21 \pm 0.25^{\mathrm{Aa}}$ & $6.12 \pm 0.16^{\mathrm{Aa}}$ \\
\hline & PUCA $3^{3)}$ & $6.14 \pm 0.20^{\mathrm{Aa}}$ & $6.26 \pm 0.15^{\mathrm{Aa}}$ & $6.25 \pm 0.16^{\mathrm{Aa}}$ & $6.28 \pm 0.17^{\mathrm{Aa}}$ & $6.20 \pm 0.27^{\mathrm{Aa}}$ \\
\hline \multirow{4}{*}{ Moisture content (\%) } & Control & $94.18 \pm 0.28^{\mathrm{Aa}}$ & $93.84 \pm 0.33^{\mathrm{Aa}}$ & $93.64 \pm 0.57^{\mathrm{Ba}}$ & $93.87 \pm 0.24^{\mathrm{Aa}}$ & $92.73 \pm 0.38^{\mathrm{Bb}}$ \\
\hline & PUCA 1 & $94.18 \pm 0.28^{\mathrm{Aa}}$ & $94.11 \pm 0.26^{\mathrm{Aa}}$ & $94.68 \pm 0.35^{\mathrm{Aa}}$ & $94.26 \pm 0.44^{\mathrm{Aa}}$ & $94.24 \pm 0.88^{\mathrm{Aa}}$ \\
\hline & PUCA 2 & $94.18 \pm 0.28^{\mathrm{Aa}}$ & $94.11 \pm 0.90^{\mathrm{Aa}}$ & $95.28 \pm 0.22^{\mathrm{Aa}}$ & $94.90 \pm 0.80^{\mathrm{Aa}}$ & $94.10 \pm 0.50^{\mathrm{Aa}}$ \\
\hline & PUCA 3 & $94.18 \pm 0.28^{\mathrm{Aa}}$ & $94.74 \pm 0.12^{\mathrm{Aa}}$ & $94.59 \pm 0.67^{\mathrm{Aa}}$ & $94.67 \pm 0.77^{\mathrm{Aa}}$ & $94.68 \pm 0.46^{\mathrm{Aa}}$ \\
\hline \multirow{4}{*}{ Firmness (kgf) } & Control & $0.65 \pm 0.06^{\mathrm{Aa}}$ & $0.64 \pm 0.05^{\mathrm{Aa}}$ & $0.66 \pm 0.08^{\mathrm{Aa}}$ & $0.63 \pm 0.06^{\mathrm{Aa}}$ & $0.59 \pm 0.10^{\mathrm{Aa}}$ \\
\hline & PUCA 1 & $0.65 \pm 0.06^{\mathrm{Aa}}$ & $0.63 \pm 0.07^{\mathrm{Aa}}$ & $0.55 \pm 0.06^{\mathrm{Aa}}$ & $0.58 \pm 0.06^{\mathrm{Aa}}$ & $0.56 \pm 0.05^{\mathrm{Aa}}$ \\
\hline & PUCA 2 & $0.65 \pm 0.06^{\mathrm{Aa}}$ & $0.62 \pm 0.07^{\mathrm{Aa}}$ & $0.58 \pm 0.04^{\mathrm{Aa}}$ & $0.56 \pm 0.07^{\mathrm{Aa}}$ & $0.55 \pm 0.09^{\mathrm{Aa}}$ \\
\hline & PUCA 3 & $0.65 \pm 0.06^{\mathrm{Aa}}$ & $0.58 \pm 0.05^{\mathrm{Aa}}$ & $0.57 \pm 0.04^{\mathrm{Aa}}$ & $0.58 \pm 0.07^{\mathrm{Aa}}$ & $0.56 \pm 0.08^{\mathrm{Aa}}$ \\
\hline
\end{tabular}

${ }^{1)} \mathrm{PUCA}$ 1: $0.5 \% \mathrm{O}_{2}+2 \% \mathrm{CO}_{2}$

${ }^{2}$ PUCA 2: $2 \% \mathrm{O}_{2}+2 \% \mathrm{CO}_{2}$

${ }^{3} \mathrm{PUCA}$ 3: $2 \% \mathrm{O}_{2}+10 \% \mathrm{CO}_{2}$.

${ }^{4)}$ Each value is mean $\pm \mathrm{SD}$.

${ }^{5}$ Mean values in the same column (A-B) or row (a-b) followed by different letters are significantly different according to Duncan's multiple range test $(\mathrm{p}<0.05)$.

받지 않는 것으로 확인되었다.

PUCA 1-3 처리구의 수분 함량은 저장 80일 동안 94.10-95.28\%를 유지하였다. 반면 저장 80 일 후 대조구는 $92.73 \%$ 의 수분 함량을 나타내 저장 초기와 비교하여 약 $1.5 \%$ 감소하였다. Zhu 등(32)과 Lee 등(33)에 의하면 수확 후 신선 배추는 수분을 94-96\% 함유한다고 보고하였는데 본 연구의 수분함량 결과도 유사한 경향을 보였다.

저장 초기 여름배추의 경도는 $0.65 \mathrm{kgf}$ 로 나타났다. 저장
80일 후 대조구와 PUCA 1-3 처리구의 경도는 0.55-0.59 $\mathrm{kgf}$ 로 저장기간 경과와 처리구간의 유의적 차이가 없었다 $(\mathrm{p}>0.05)$. Lee 등(13)은 저장기간이 경과함에 따라 배추에 증산작용과 수분 감소로 외피가 질겨지거나 pectin 분해로 인한 조직의 연화가 발생하여 경도가 변화한다고 보고하였 다. 본 연구에서 경도를 측정한 배추 시료는 저장 중 건조된 겉잎을 제거하고 줄기 부위를 이용하였기 때문에 대조구와 PUCA 처리구 간에 차이를 보이지 않은 것으로 판단된다.

Table 3. Changes in the reducing sugar content and soluble solids content of the kimchi cabbages treated with pallet unit-controlled atmosphere packaging during storage

\begin{tabular}{|c|c|c|c|c|c|c|}
\hline \multirow{2}{*}{$\begin{array}{l}\text { Quality } \\
\text { parameter }\end{array}$} & \multirow{2}{*}{ Treatment } & \multicolumn{5}{|c|}{ Storage period (day) } \\
\hline & & 0 & 20 & 40 & 60 & 80 \\
\hline \multirow{4}{*}{$\begin{array}{l}\text { Reducing sugar content } \\
(\mathrm{mg} / \mathrm{g})\end{array}$} & Control & $17.86 \pm 0.37^{4) \mathrm{Aas})}$ & $17.29 \pm 0.91^{\mathrm{Aa}}$ & $16.61 \pm 1.61^{\text {Aab }}$ & $16.26 \pm 0.92^{\text {Aab }}$ & $15.33 \pm 0.41^{\mathrm{Ab}}$ \\
\hline & PUCA $1^{1)}$ & $17.86 \pm 0.37^{\mathrm{Aa}}$ & $16.25 \pm 1.94^{\mathrm{Aab}}$ & $16.07 \pm 1.37^{\mathrm{Aab}}$ & $16.08 \pm 0.69^{\mathrm{Aab}}$ & $15.32 \pm 1.21^{\mathrm{Ab}}$ \\
\hline & PUCA $2^{2)}$ & $17.86 \pm 0.37^{\mathrm{Aa}}$ & $17.95 \pm 1.32^{\mathrm{Aa}}$ & $16.33 \pm 0.36^{\mathrm{Aab}}$ & $15.82 \pm 2.00^{\mathrm{Aab}}$ & $15.25 \pm 0.86^{\mathrm{Ab}}$ \\
\hline & PUCA $3^{3)}$ & $17.86 \pm 0.37^{\mathrm{Aa}}$ & $16.93 \pm 1.09^{\mathrm{Aab}}$ & $16.08 \pm 1.67^{\mathrm{Aab}}$ & $15.86 \pm 0.23^{\mathrm{Aab}}$ & $15.63 \pm 1.30^{\mathrm{Ab}}$ \\
\hline \multirow{4}{*}{$\begin{array}{l}\text { Soluble solids content } \\
\left.\text { ( }{ }^{\circ} \text { Brix }\right)\end{array}$} & Control & $4.77 \pm 0.12^{\mathrm{Aa}}$ & $5.07 \pm 0.80^{\mathrm{Aa}}$ & $4.80 \pm 0.36^{\mathrm{Aa}}$ & $4.97 \pm 0.21^{\mathrm{Aa}}$ & $5.17 \pm 0.60^{\mathrm{Aa}}$ \\
\hline & PUCA 1 & $4.77 \pm 0.12^{\mathrm{Aa}}$ & $4.97 \pm 0.42^{\mathrm{Aa}}$ & $4.80 \pm 0.29^{\mathrm{Aa}}$ & $4.53 \pm 0.35^{\mathrm{Aa}}$ & $4.53 \pm 0.35^{\mathrm{Aa}}$ \\
\hline & PUCA 2 & $4.77 \pm 0.12^{\mathrm{Aa}}$ & $4.63 \pm 0.60^{\mathrm{Aa}}$ & $4.50 \pm 0.60^{\mathrm{Aa}}$ & $4.60 \pm 0.36^{\mathrm{Aa}}$ & $4.70 \pm 0.30^{\mathrm{Aa}}$ \\
\hline & PUCA 3 & $4.77 \pm 0.12^{\mathrm{Aa}}$ & $4.63 \pm 0.28^{\mathrm{Aa}}$ & $4.30 \pm 0.52^{\mathrm{Aa}}$ & $4.67 \pm 0.21^{\mathrm{Aa}}$ & $4.47 \pm 0.52^{\mathrm{Aa}}$ \\
\hline
\end{tabular}

${ }^{1)}$ PUCA 1: $0.5 \% \mathrm{O}_{2}+2 \% \mathrm{CO}_{2}$

${ }^{2} \mathrm{PUCA}$ 2: $2 \% \mathrm{O}_{2}+2 \% \mathrm{CO}_{2}$.

${ }^{3} \mathrm{PUCA} 3: 2 \% \mathrm{O}_{2}+10 \% \mathrm{CO}_{2}$

${ }^{4}$ Each value is mean $\pm \mathrm{SD}$.

${ }^{5}$ Mean values in the same column (A) or row (a-b) followed by different letters are significantly different according to Duncan's multiple range test $(\mathrm{p}<0.05)$. 
저장 중 여름배추의 환원당 함량과 가용성 고형물 함량 변화

저장 전 여름배추 시료의 환원당 함량은 $17.86 \mathrm{mg} / \mathrm{g}$ 이었 지만 저장기간이 증가함에 따라 감소하는 경향을 나타냈다 (Table 3). 저장 80일 후 PUCA 1-3 처리구의 환원당 함량은 $15.25-15.63 \mathrm{mg} / \mathrm{g}$ 으로 대조구의 $15.33 \mathrm{mg} / \mathrm{g}$ 과 비교하여 유 의적 차이를 보이지 않았다 $(\mathrm{p}>0.05) . \mathrm{Kim}$ 등(8)에서 국산 가을배추의 환원당 함량은 90 일 저장 후 $30-40 \%$ 감소하였 지만 그물망, 골판지 박스와 플라스틱 박스와 $\mathrm{PE}$ 필름 포장 방법에 따른 뚜렷한 차이는 보이지 않았다는 보고는 본 연구 결과와 유사하였다.

저장 초기 여름배추의 가용성 고형물 함량은 저장 초기 $4.77{ }^{\circ} \mathrm{Brix}$ 이였으며 저장 80 일 후 PUCA 1,2 와 3 처리구의 가용성 고형물 함량은 각각 $4.53,4.70$ 과 $4.47{ }^{\circ} \mathrm{Brix}$ 로 나타 나 대조구의 $5.17{ }^{\circ} \mathrm{Brix}$ 와 비교하여 유의적 차이를 보이지 않았다(Table 3). Eum 등(21)은 0, 2 와 $5^{\circ} \mathrm{C}$ 저장 3 주까지 여름배추의 가용성 고형물 함량은 저장 온도별 유의적 차이 를 보이지 않았다고 보고하였다. $\mathrm{Bae}$ 등(4)에서 예냉 또는 예건 및 $\mathrm{HDPE}$ 필름 liner 처리한 고랭지 배추의 가용성 고형물 함량은 저장 8 주 후 $2.59-2.86{ }^{\circ} \mathrm{Brix}$ 로 각 처리구 간에 차이를 확인하지 못했다고 보고하였다. 한편 배추와 비교하여 가용성 고형물 함량이 상대적으로 높고 호흡 급등 형인 무화과는 $\mathrm{CA}$ 저장 중 $\mathrm{CO}_{2}$ 농도가 높을수록 가용성 고형물 함량 증가가 효과적으로 지연되었다는 연구 결과가 보고된 바 있다(29).

따라서 이전 연구와 본 연구 결과를 종합하여 파렛트 포장 내부의 조절된 기체 환경은 저장 중 여름배추의 환원 당 함량과 가용성 고형물 함량 변화에 영향을 미치지 않은 것으로 판단된다.

\section{저장 중 여름배추의 총 페놀 화합물과 총 glucosinolates 함량 변화}

배추는 glucosinolate류와 페놀 화합물 등 생리활성 성분 의 함량이 높다(34). 따라서 저장 중 배추의 기능성 성분의 함량 변화 추이를 분석하는 것은 저장 안정성을 판단하는 지표로서 중요하다. Pallet unit 기체 제어 조건에 따른 여름 배추의 총 페놀 화합물과 총 glucosinolates 함량 변화는 Table 4에 나타내었다.

대조구의 총 페놀 화합물 함량은 저장기간이 증가함에 따라 감소하여 저장 80 일후 $167.42 \mathrm{mg} \mathrm{GAE} / 100 \mathrm{~g}$ 을 나타 냈다. 이는 대조구의 총 페놀 화합물 함량이 저장 초기에 비해 약 $56 \mathrm{mg} \mathrm{GAE} / 100 \mathrm{~g}$ 감소한 결과이다. 저장 중 PUCA 1 과 3 처리구의 총 페놀 화합물 함량 변화는 대조구 결과와 유사하였다. 저장 초기 PUCA 1과 3 처리구의 총 페놀 화합 물 함량은 $223.70 \mathrm{mg} \mathrm{GAE} / 100 \mathrm{~g}$ 이었지만 저장 80 일 후 각각 155.56 와 $172.91 \mathrm{mg} \mathrm{GAE} / 100 \mathrm{~g}$ 까지 감소하였다. 한편 저장 80일 후 PUCA 2 처리구는 대조구, PUCA 1 과 3 처리구 와 비교하여 유의적으로 $(\mathrm{p}<0.05)$ 높은 총 페놀 화합물 함량 을 보였다. Hounsome 등(35)은 6개월 장기 저장 중 white cabbage(Brassica oleracea L. var. capitata)의 항산화 화합물 함량 변화는 수확 후 노화와 곰팡이 감염에 대한 반응과 관련 있음을 보고하였다.

저장 초기 여름배추의 총 glucosinolates 함량은 $16.72 \mu$ $\mathrm{mol} / \mathrm{g}$ 이었다. 한편 저장 80 일 후 대조구, PUCA 1,2 와 3 처리구의 총 glucosinolates 함량은 6.21-7.28 $\mu \mathrm{mol} / \mathrm{g}$ 으로 저 장기간이 경과함에 따라 감소하는 경향을 보였지만 처리구 간에 유의적 차이는 나타나지 않았다 $(\mathrm{p}>0.05)$. Hodges 등 (36)은 $3 \% \mathrm{O}_{2}$ 와 $5 \% \mathrm{CO}_{2} \mathrm{CA}$ 와 대기 저온환경에서 꽃양배추 를 56일간 저장한 결과 두 처리구 간에 총 glucosinolates 함량 차이는 보이지 않았다고 보고하였는데 본 연구결과와 유사하였다.

Table 4. Changes in the total phenolic content and total glucosinolate content of the kimchi cabbages treated with pallet unit-controlled atmosphere packaging during storage

\begin{tabular}{ccccccc}
\hline \multirow{2}{*}{ parameter } & Treatment & \multicolumn{5}{c}{ Storage period (day) } \\
\cline { 3 - 7 } & & 0 & 20 & 40 & 60 & 80 \\
\hline \multirow{2}{*}{$\begin{array}{c}\text { Total phenolic content } \\
\text { (mg GAE/100 g) }\end{array}$} & PUCA 1 & $223.70 \pm 6.28^{\mathrm{Aa}}$ & $194.38 \pm 9.25^{\mathrm{ABb}}$ & $186.00 \pm 3.45^{\mathrm{Ac}}$ & $169.38 \pm 4.13^{\mathrm{Cd}}$ & $155.56 \pm 3.85^{\mathrm{Ce}}$ \\
& PUCA 2 & $223.70 \pm 6.28^{\mathrm{Aa}}$ & $200.56 \pm 3.33^{\mathrm{Ab}}$ & $192.42 \pm 5.20^{\mathrm{Add}}$ & $197.03 \pm 5.01^{\mathrm{Abc}}$ & $189.58 \pm 7.49^{\mathrm{Ad}}$ \\
& PUCA 3 & $223.70 \pm 6.28^{\mathrm{Aa}}$ & $195.26 \pm 4.32^{\mathrm{ABb}}$ & $172.03 \pm 15.46^{\mathrm{Bc}}$ & $179.87 \pm 10.85^{\mathrm{Bc}}$ & $172.91 \pm 3.64^{\mathrm{Bc}}$ \\
\multirow{2}{*}{$\begin{array}{c}\text { Total glucosinolate content } \\
(\mu \text { mol/g) }\end{array}$} & Control & $16.72 \pm 3.93^{\mathrm{Aa}}$ & $15.31 \pm 1.03^{\mathrm{Aa}}$ & $13.67 \pm 0.88^{\mathrm{Aa}}$ & $8.77 \pm 0.76^{\mathrm{Ab}}$ & $6.93 \pm 0.40^{\mathrm{Ab}}$ \\
& PUCA 1 & $16.72 \pm 3.93^{\mathrm{Aa}}$ & $15.49 \pm 1.21^{\mathrm{Aa}}$ & $13.80 \pm 0.78^{\mathrm{Aa}}$ & $8.99 \pm 0.80^{\mathrm{Ab}}$ & $6.35 \pm 0.65^{\mathrm{Ab}}$ \\
& PUCA 2 & $16.72 \pm 3.93^{\mathrm{Aa}}$ & $15.72 \pm 1.15^{\mathrm{Aa}}$ & $13.99 \pm 0.99^{\mathrm{Aa}}$ & $9.96 \pm 0.92^{\mathrm{Ab}}$ & $7.28 \pm 1.09^{\mathrm{Ab}}$ \\
& PUCA 3 & $16.72 \pm 3.93^{\mathrm{Aa}}$ & $15.02 \pm 1.15^{\mathrm{Aa}}$ & $13.85 \pm 0.52^{\mathrm{Aa}}$ & $9.13 \pm 0.84^{\mathrm{Ab}}$ & $6.21 \pm 0.92^{\mathrm{Ab}}$ \\
\hline
\end{tabular}

1)PUCA 1: $0.5 \% \mathrm{O}_{2}+2 \% \mathrm{CO}_{2}$.

${ }^{2)}$ PUCA 2: $2 \% \mathrm{O}_{2}+2 \% \mathrm{CO}_{2}$.

${ }^{3} \mathrm{PUCA}$ 3: $2 \% \mathrm{O}_{2}+10 \% \mathrm{CO}_{2}$

${ }^{4)} \mathrm{Each}$ value is mean $\pm \mathrm{SD}$.

${ }^{5}$ Mean values in the same column $(\mathrm{A}-\mathrm{C})$ or row $(\mathrm{a}-\mathrm{e})$ followed by different letters are significantly different according to Duncan's multiple range test $(\mathrm{p}<0.05)$. 


\section{요 약}

본 연구는 개발한 PUCA packaging 시스템을 이용하여 기체 환경 조성에 따른 저장 중 여름배추의 생리학적 특성 과 이화학적 품질 변화를 구명하고자 수행하였다. 대기 환 경에서 저장한 대조구의 중량감모율은 저장기간이 경과함 에 따라 증가하여 저장 80 일 후 $29.07 \%$ 인 반면 PUCA 1-3 처리구는 $1.58 \%$ 이하로 관찰되었다. 또한 저장 80 일 후 PUCA 1-3 처리구의 정선손실률과 내부장해 및 부패발생률 은 각각 25.68-26.54\%와 17.39-19.05\%로 대조구에 비해 유 의적으로 $(\mathrm{p}<0.05)$ 낮게 나타났으며 수분 함량은 94.10$94.68 \%$ 로 저장 초기 수준을 유지하였다. $2 \% \mathrm{O}_{2}+10 \%$ $\mathrm{CO}_{2}$ 조건에서 저장한 PUCA 3 처리구의 호흡률은 저장기 간 동안 일정하게 유지하였지만 대조구, PUCA 1 과 2 처리 구는 저장기간이 증가함에 따라 감소하는 경향을 보였다. 총 페놀 화합물 함량의 경우, $2 \% \mathrm{O}_{2}+2 \% \mathrm{CO}_{2}$ 기체 환경 조건의 PUCA 2 처리구가 저장 80 일 후 $189.58 \mathrm{mg} \mathrm{GAE} / 100$ $\mathrm{g}$ 으로 나타나 대조구와 PUCA 1 과 3 처리구에 비해 높은 함량을 보였다. 한편 저장 중 PUCA 1-3 처리구의 $\mathrm{pH}$, 경도, 환원당 함량, 가용성 고형물 함량 및 총 glucosinolates 함량 은 대조구와 비교하여 유의적 차이를 보이지 않았다 ( $p>0.05)$. 따라서 PUCA packaging 시스템을 이용한 CA 기 술은 저온저장 중 여름배추의 품질유지와 노화억제에 상승 효과를 나타내 저장한계기간을 연장할 수 있을 것으로 판단 된다. 향후 PUCA packaging 시스템은 상용화를 위해 습도 제어 기능을 보완하여 포장 내부의 상대습도 $90-95 \% \mathrm{RH}$ 유지에 따른 배추의 저장 안정성 추가 연구가 필요하다.

\section{감사의 글}

본 연구는 2019년 농촌진흥청 공동연구사업(과제번호: PJ013404012019)의 지원에 의해 이루어진 것으로 감사드 립니다.

\section{References}

1. Lee IK, Hong SJ, Yeong YR, Park SW, Ku OS (2001) Effects of postharvest predrying on storability of 'Norang' Chinese cabbage. Kor J Hort Sci Technol, 19, 521-525

2. Seong GU, Chung HS, Chung SK (2015) The cutting process improvement for cut kimchi cabbage quality. Korean J Food Preserv, 22, 154-157

3. Korea Agro-Fisheries \& Food Trade Corporation. http://www.atfis.or.kr/article/M001040000/view.do?artic
leId=2898 (accessed January 2019)

4. Bae SJ, Eum HL, Kim BS, Yoon J, Hong SJ (2015) Comparison of the quality of highland-grown Kimchi cabbage 'Choon Gwang' during cold storage after pretreatments. Kor J Hort Sci Technol, 33, 233-241

5. Jeong JK, Park SE, Lee SM, Choi HS, Kim SH, Park KY (2011) Quality changes of brined baechu cabbage prepared with low temperature stored baechu cabbages. J Korean Soc Food Sci Nutr, 40, 475-479

6. Ku KH, Jeong MC, Chung SK (2013) Industrialization of salted Chinese cabbages and fresh-cut Chinese cabbage. Food Sci Industry, 46, 2-11

7. Lee YJ, Lee HO, Kim JY, Kim BS (2017) Effect of various loading methods on freshness of spring kimchi cabbage. J Korean Soc Food Cult, 32, 303-310

8. Kim BS, Nahmgung B, Kim MJ (2001) Effect of packaging and loading conditions on the quality of late autumn Chinese cabbage during cold storage. Kor J Food Sci Technol, 8, 23-29

9. In BC, Kim JG (2008) Effect of precooling and harvesting at different times on respiration, browning and microbial growth of fresh-cut iceberg lettuce. Kor J Hort Sci Technol, 26, 258-264

10. Yang YJ, Jeong JC, Chang TJ, Lee SY, Pek UH (1993) $\mathrm{CO}_{2}$ Production and trimming loss affected by storage temperature and packaging methods in Chinese cabbage (Brassica campestris L. ssp. Pekinensis) grown in spring. J Kor Soc Hort Sci, 34, 267-272

11. Simoes AD, Allende A, Tudela JA, Puschmann R, Gil MI (2011) Optimum controlled atmospheres minimise respiration rate and quality losses while increase phenolic compounds of baby carrots. LWT-Food Sci Technol, 44, 277-283

12. Aaby K, Haffner K, Skrede G (2002) Aroma quality of Gravenstein apples influenced by regular and controlled atmosphere storage. LWT-Food Sci Technol, 35, 254-259

13. Lee YJ, Lee HO, Kim JY, Kim BS (2016) Effect of Pallet-unit MAP treatment on freshness extension of spring Chinese cabbage. J Korean Soc Food Cult, 31, 634-642

14. Osher Y, Chalupowicz D, Maurer D, Ovadia-Sadeh A, Lurie S, Fallik E, Kenigsbuch D (2018) Summer storage of cabbage. Postharvest Biol Technol, 145, 144-150

15. Zhu Z, Wu X, Geng Y, Sun DW, Chen H, Zhao Y, Zhou W, Li X, Pan H (2018) Effects of modified atmosphere vacuum cooling (MAVC) on the quality of three different leafy cabbages. LWT-Food Sci Technol, 
94, 190-197

16. Kim BS, Kim MJ, Kim OW, Kim GH (2001) Quality changes of winter Chinese cabbage by different packing and loading during cold storage. Kor J Postharvest Sci Technol, 8, 30-36

17. Lee HO, Lee YJ, Kim JY, Kim BS (2018) Effect of combined pallet unit MAP and plasma treatment for extending the freshness of spring Kimchi cabbage. Kor J Hort Sci Technol, 36, 224-236

18. Eum HL, Bae SJ, Kim BS, Yoon J, Kim J, Hong SJ (2013) Postharvest quality changes of kimchi cabbage 'Choongwang' cultivar as influenced by postharvest treatments. Kor J Hort Sci Technol, 31, 429-436

19. Hong SJ, Kim BS, Kim BS, Eum HL (2018) Responses to 1-MCP during storage of Kimchi cabbage Ryouckgwang cultivar. Protected Hort Plant Fac, 27, 125-131

20. Kim MN, Park SH, Park CW, Choi SY, Choi DS, Kim JS, Kim YH, Lee SJ (2018) Quality estimation of winter Chinese cabbage stored in purge type of controlled atmosphere storage. Food Eng Prog, 22, 59-66

21. Eum HL, Kim BS, Yang YJ, Hong SJ (2013) Quality evaluation and optimization of storage temperature with eight cultivars of Kimchi cabbage produced in summer at highland areas. Kor J Hort Sci Technol, 31, 211-218

22. Fonseca SC, Gil L, Manso MC, Cunha LM (2018) Modelling the influence of storage temperature and time after cutting on respiration rate of diced red onions (Allium cepa L. cv. Vermelha da Povoa). Postharvest Biol Technol, 140, 27-33

23. Fonseca SC, Oliveira FA, Brecht JK (2002) Modelling respiration rate of fresh fruits and vegetables for modified atmosphere packages: a review. J Food Eng, 52, 99-119

24. Yang D, Li D, Xu W, Liao R, Shi J, Fu Y, Wang J, Wang Y, He X (2018) Design and application of a passive modified atmosphere packaging for maintaining the freshness of Chinese cabbage. LWT-Food Sci Technol, 94, 136-141

25. Miller GL (1959) Use of dinitrosalicylic acid reagent for determination of reducing sugar. Anal Chem, 31, 426-428

26. Porter KL, Klieber A, Collins G (2003) Chilling injury limits low temperature storage of 'Yuki' Chinese cabbage. Postharvest Biol Technol, 28, 153-158
27. Hong S, Kim B, Park N, Eum H (2017) Influence of nitrogen fertilization on storability and the occurrence of black speck in spring kimchi cabbage. Korean J Hortic Sci, 35, 727-736

28. Menniti AM, Maccaferri M, Folchi A (1997) Physio-pathological responses of cabbage stored under controlled atmospheres. Postharvest Biol Technol, 10, 207-212

29. Bahar A, Lichter A (2018) Effect of controlled atmosphere on the storage potential of Ottomanit fig fruit. Sci Hortic, 227, 196-201

30. Bai J, Saftner RA, Watada AE (2003) Characteristics of fresh-cut honeydew (Cucumis xmelo L.) available to processors in winter and summer and its quality maintenance by modified atmosphere packaging. Postharvest Biol Technol, 28, 349-359

31. Park SH, Chun HH, Choi DS, Choi SR, Kim JS, Oh SS, Lee JS (2015) Development of controlled atmosphere container using gas separation membrane for the storage of agricultural products. Food Eng Prog, 19, 70-75

32. Zhu Z, Geng Y, Sun DW (2019) Effects of operation processes and conditions on enhancing performances of vacuum cooling of foods: A review. Trends Food Sci Technol, 85, 67-77

33. Lee JS, Park SH, Lee YS, Lim BS, Yim SC, Chun CH (2008) Characteristics of growth and salting of Chinese cabbage after spring culture analyzed by cultivar and cultivation method. Korean J Food Preserv, 15, 43-48

34. Cartea ME, Francisco M, Soengas P, Velasco P (2011) Phenolic compounds in Brassica vegetables. Molecules, $16,251-280$

35. Hounsome N, Hounsome B, Tomos D, Edwards-Jones G (2009) Changes in antioxidant compounds in white cabbage during winter storage. Postharvest Biol Technol, 52, 173-179

36. Hodges DM, Munro KD, Forney CF, McRae KB (2006) Glucosinolate and free sugar content in cauliflower (Brassica oleracea var. botrytis cv. Freemont) during controlled-atmosphere storage. Postharvest Biol Technol, 40, 123-132 